\title{
Comparative Study on the Effects of Chloroquine and Artesunate on Histopathological Damages Caused by Plasmodium berghei in Four Vital Organs of Infected Albino Mice
}

\author{
O. T. Soniran, ${ }^{1}$ O. A. Idowu, ${ }^{1}$ O. L. Ajayi, ${ }^{2}$ and I. C. Olubi ${ }^{1}$ \\ ${ }^{1}$ Department of Biological Sciences, University of Agriculture, PMB 2240, Abeokuta, Nigeria \\ ${ }^{2}$ College of Veterinary Medicine, University of Agriculture, PMB 2240, Abeokuta, Nigeria
}

Correspondence should be addressed to O. T. Soniran, temidayoolajoju@yahoo.com

Received 13 December 2011; Revised 23 February 2012; Accepted 30 April 2012

Academic Editor: Donatella Taramelli

Copyright (c) 2012 O. T. Soniran et al. This is an open access article distributed under the Creative Commons Attribution License, which permits unrestricted use, distribution, and reproduction in any medium, provided the original work is properly cited.

\begin{abstract}
The aim of the present study was to investigate the positive influence of chloroquine and artesunate on the pathological damages caused by Plasmodium berghei on vital organs of mice in an established infection. Healthy adult albino mice with average weight of $25 \mathrm{~g}$ were used for the study. Treated group was administered orally with $100 \mathrm{mg} / \mathrm{kg}$ of chloroquine and artesunate, respectively. Control animals were given water for the same period. Histological examination of the liver, spleen, lungs, and kidney revealed absence of accumulation of iron (haemosiderosis) in the liver, thickened alveolar wall, and interstitial mononuclear cells infiltration in the lungs of the artesunate group, while absence of emphysema in the lungs and megakaryoblast hyperplasia in the spleen was observed in the chloroquine group. Lymphoid hypoplasia in the chloroquine group and megakayoblast hyperplasia in the artesunate group were observed but not in the control group. Thus, the use of these drugs especially under the practice of selfmedication should be prohibited in lands where they are still in use as antimalaria medicine.
\end{abstract}

\section{Introduction}

Malaria is a disease that is caused in humans by parasites of the Plasmodium species through the bite of infected anopheles mosquitoes. About 3.3 billion people-half of the world's population-are at risk of malaria. Every year, this leads to about 250 million malaria cases and nearly one million deaths [1]. Nigeria is known for high prevalence of malaria [2-4] and it is a leading cause of morbidity and mortality in the country [3]. WHO recently listed Nigeria among high burden countries with limited evidence of decrease in malaria cases [5]. Cinchona bark is one of the most naturally occurring drugs. This natural product was used by the inhabitants of Peru to control malaria, and the Jesuits introduced this practice to Europe during the 1640s where it was rapidly accepted. However, it was not until 1820 s that the active ingredient quinine was extracted from the bark and isolated. It was named by the French chemists Pierre Joseph Pelletier and Joseph Bienaimé Caventou [6].
Treatment of malaria involves supportive measures as well as specific antimalarial drugs. With early diagnosis and effective treatment, someone with malaria can expect a complete recovery [7]. There are several families of drugs used to treat malaria. Chloroquine (CQ) which was introduced in the 1940s and for many decades served as a cheap and reliable drug is no longer effective against $P$. falciparum due to the increasing emergence of chloroquine-resistant strains of the malaria parasite $[8,9]$. Due to widespread reports of chloroquine ineffectiveness against the malaria parasite in endemic countries outside the African continent, the Federal Government of Nigeria officially banned the use of chloroquine in 2004. This policy was not effected until 2010 [10]. However, chloroquine is still in circulation because it is still purchased over the counter in chemist stores. In the face of this challenge facing chemotherapy of malaria, artemisinin and its derivatives (artesunate, artemether, arteether, and dihydroartemisinin) have given renewed hope for combating resistant malaria $[11,12]$. Artesunate (ART) is part of the 
artemisinin group of drugs that treat malaria. It is a semisynthetic derivative of artemisinin. Clinical evidence of drug resistance to artesunate was first reported in Western Cambodia, where artemisinin monotherapy is common [13]. Over the past decade, a new group of antimalarials - known as artemisinin-based combination therapies - has brought new hope in the fight against malaria [5]. In malaria endemic areas such as Nigeria, self-medication is quite common and purchase of antimalarials in the open market is rampant [14].

This study aims to assess the antimalarial efficacy of chloroquine and artesunate and their effects on pathology of malaria in vital organs of albino mice.

\section{Materials and Methods}

2.1. Experimental Design. A total of 20 adult albino mice weighing between $20 \mathrm{~g}$ to $22 \mathrm{~g}$ were obtained from the Nigerian Institute of Medical Research, Yaba, Lagos (Nigeria) and randomly divided into four groups: A, B, C, and D. Group A represented uninfected normal control. Groups B, $\mathrm{C}$, and D were inoculated with the malaria parasites. Group B served as the infected but untreated control, while groups $\mathrm{C}$ and $\mathrm{D}$ received daily doses of $100 \mathrm{mg} / \mathrm{kg}$ of chloroquine and artesunate, respectively. Malaria infection was established on the 5th day before commencement of treatment in the experimental mice. The mice were treated for ten days before sacrificing them for histological study.

2.2. Malaria Parasite. The chloroquine-sensitive Plasmodium berghei NK65 strain used for this study was obtained from the Biochemistry Department, Nigerian Institute of Medical Research, Yaba, Lagos, Nigeria. The infection of the recipient mice was initiated by needle passage of the parasite preparation from the donor to healthy test animals via an intraperitoneal route as described by David et al. [15] and Peter and Anatoli [16]. Briefly, P. berghei-infected red blood cells obtained from the tail vein of infected mice was diluted with phosphate buffered saline (PBS) so that each $0.2 \mathrm{~mL}$ that was subsequently injected contained approximately $10^{3}$ infected red cells (parasite) per kilogram of body weight.

2.3. Location and Duration of Study. This study was conducted in the Animal House of the Biological Sciences Department, College of Natural Sciences, University of Agriculture, Abeokuta, Nigeria. Animal acclimatization, drug administration, histological studies, and evaluation of results lasted for four months (November 2009 to February 2010).

2.4. Drug Administration. The test drugs (artesunate and chloroquine phosphate) used for this experiment were prepared in aqueous solution and administered orally at a dose level of $100 \mathrm{mg} / \mathrm{kg}$ body wt for ten days. The dose of the treatment was chosen based on our previous data [17] where a dose of $100 \mathrm{mg} / \mathrm{kg}$ produced parasite clearance.

2.5. Histological Study. Histological studies were carried out in the Pathology Laboratory, College of Veterinary Sciences, University of Agriculture, Abeokuta. The animals were sacrificed by cervical dislocation 24 hour after the last dose on the 10th day of the respective treatment and the organs were harvested.

Primarily, pathological changes were observed in six main organs-liver, kidney, spleen, lungs, brain, and the heart - of the different groups of experimental mice.

For light microscopic examination, tissues from each group were fixed with $10 \%$ buffered formalin, embedded with paraffin. After routine processing, paraffin sections of each tissue were cut into $5 \mu \mathrm{m}$ thickness and stained with haematoxylin and eosin [4]. The photomicrographs of the relevant stained sections were taken with the aid of a light microscope.

The following scores were used to grade the degree of histopathological changes or lesions observed in the organs: not present $(-)$, very mild $(+)$, mild $(++)$, moderate $(+++)$, and severe $(++++)$.

\section{Results}

Microscopic examination of blood films prepared from blood sample collected from the tail showed that the inoculums produced a mean parasitaemia of not less than $2 \%$ in 5 days before starting treatment.

No parasitaemia was observed in the artesunate group on the second day of treatment while CQ cleared all parasitaemia on the third day of treatment.

Physical examination of the internal organs after dissection of experimental mice showed mild enlargement of the spleen (splenomegaly) in the group treated with artesunate. The liver, lungs, and kidneys of the two groups treated with chloroquine and artesunate, respectively, were without macroscopic changes.

Histological studies revealed some damages caused by the malaria parasite and extent of reduction of these damages by the administered drugs, for example, the accumulation of iron in the liver and spleen (haemosiderosis), death of cells of the liver (hepatic necrosis), marked damage of the nephron in the kidney (tubular nephrosis) (Tables 1 and 3), and gradual breakdown of the alveoli walls (emphysema) in the lungs (Table 4). All these damages were severe in the control group. However, observation of the heart and brain showed no visible lesion at all. The degrees of damages caused in the organs were scored or assigned as follows: not present $(-), 1$ to 4 foci/section examined ( + ), 5 to 8 foci/section examined $(++),>9$ foci/section examined $(++++)$. Tubular nephrosis was graded $(++)$ when scattered cells were detected with pyknotic, karyorrhexis, karyolysis nuclei, or loss of polarity, $(+++)$ when these changes were present in larger sections of a tubule, and $(++++)$ when multiple tubules in an area were affected.

\subsection{Effect of Chloroquine and Artesunate on Pathology in the} Liver. haemosiderosis and hemozoin were observed in the liver. The effect of Artesunate at reducing the pathologies caused by the malaria parasite was more noticeable compared to that of Chloroquine. Haemosiderosis and kupffer cell hyperplasia were not observed in the artesunate group 
TABLE 1: Histopathological effects on the liver.

\begin{tabular}{|c|c|c|c|}
\hline \multirow{2}{*}{ Pathological effects } & \multicolumn{2}{|c|}{ Treatment } & \multirow{2}{*}{$\begin{array}{c}\text { Control } \\
\text { INT }\end{array}$} \\
\hline & CQ & ART & \\
\hline Kupffer cell hyperplasia & ++ & - & ++++ \\
\hline Haemosiderosis & ++ & - & ++++ \\
\hline Hepatic necrosis & ++ & ++ & ++++ \\
\hline Periportal mononuclear cells infiltration & + & + & - \\
\hline
\end{tabular}

CQ: chloroquine, ART: artesunate, INT: infected but not treated. Not present $(-)$, very mild $(+)$, mild $(++)$, moderate $(+++)$, and severe $(++++)$.

TABLE 2: Histopathological effects on the kidney.

\begin{tabular}{|c|c|c|c|}
\hline \multirow{2}{*}{ Pathological effects } & \multicolumn{2}{|c|}{ Treatment } & \multirow{2}{*}{$\begin{array}{c}\text { Control } \\
\text { INT }\end{array}$} \\
\hline & CQ & ART & \\
\hline Tubular nephrosis & ++ & ++ & ++++ \\
\hline $\begin{array}{l}\text { Perivascular interstitial mononuclear cell } \\
\text { infiltration }\end{array}$ & - & - & ++++ \\
\hline
\end{tabular}

CQ: chloroquine, ART: artesunate, INT: infected but not treated. Not present $(-)$, very mild $(+)$, mild $(++)$, moderate $(+++)$, and severe $(++++)$.

TABLE 3: Histopathological effects on the spleen.

\begin{tabular}{|c|c|c|c|}
\hline \multirow{2}{*}{ Pathological effects } & \multicolumn{2}{|c|}{ Treatment } & \multirow{2}{*}{$\begin{array}{c}\text { Control } \\
\text { INT }\end{array}$} \\
\hline & CQ & ART & \\
\hline Haemosiderosis & ++ & ++ & ++++ \\
\hline Lymphoid hypoplasia & +++ & - & - \\
\hline Megakaryoblast hyperplasia & - & ++++ & - \\
\hline
\end{tabular}

CQ: chloroquine, ART: artesunate, INT: infected but not treated. Not present $(-)$, very mild $(+)$, mild $(++)$, moderate $(+++)$, and severe $(++++)$.

but these changes were mildly observed in the chloroquine group. The two drugs also mildly Hepatic necrosis was mildly seen in the two treatment groups. However, all these pathological changes were severe in the control group (Table 1).

3.2. Effect of Chloroquine and Artesunate on Pathology in the Kidney. Chloroquine and artesunate prevented the infiltration of perivascular interstitial mononuclear cells in treated mice but mildly reduced tubular nephrosis unlike the control group which was severe (Table 2).

3.3. Effect of Chloroquine and Artesunate on Pathology in the Spleen. Hemozoin was observed more in the untreated control with few haemosiderosis. There was no loss of cellular architecture. CQ and ART treatment showed mild reduction of these pathologies caused by the parasite in the tissues of the spleen compared to the control which was severe (Table 3).

3.4. Effect of Chloroquine and Artesunate on Pathology in the Lung. CQ completely reduced emphysema unlike ART which mildly reduced it. ART totally reduced the thickening of the alveolar wall, but CQ mildly reduced it. The two
TABLE 4: Histopathological effects on the lung.

\begin{tabular}{lccc}
\hline \multirow{2}{*}{ Pathological effects } & \multicolumn{2}{c}{ Treatment } & Control \\
& CQ & ART & INT \\
\hline Emphysema & - & ++ & ++++ \\
Thickened alveolar wall & ++ & - & ++++ \\
Interstitial mononuclear cells infiltration & - & - & ++++ \\
\hline
\end{tabular}

CQ: chloroquine, ART: artesunate, INT: infected but not treated. Not present $(-)$, very mild $(+)$, mild $(++)$, moderate $(+++)$, and severe $(++++)$.

drugs completely reduced the infiltration of interstitial mononuclear cells when compared to the control (Table 4).

3.5. Histopathological Effects of CQ and ART on the Organs. Moderate lymphoid hypoplasia and severe megakaryoblast hyperplasia were observed in the spleens of groups treated with chloroquine and artesunate, respectively. Likewise, mild periportal mononuclear cells infiltration was observed in the liver, but these side effects were not observed in the untreated infected control (Tables 1 and 3).

\section{Discussion}

The total clearance of parasitaemia in the experimental mice by artesunate and chloroquine on the third and fifth days, respectively, showed that the drugs are still effective against malaria parasites that have not developed resistance yet.

The severe damages observed in the liver of the control mice were as a result of parasite life cycle during erythrocytic stages in the blood stream. At the early stage of the exoerythrocytic phase, a parasite infects the hepatocyte and multiplies asexually releasing merozoites which rupture their host cells. The liberated merozoites leave the liver and enter the blood stream where they infect the red blood cells [18]. In response to the damage caused, macrophages (Kupffer cells) in the liver actively proliferate (kupffer cell hyperplasia) breaking down ruptured red blood cells by phagocytic action and splitting the haemoglobin molecules. This results into pathological effects like accumulation of iron in the liver (haemosiderosis), which is usually linked with anaemia and could sometimes lead to liver cirrhosis, a condition of decreased liver function if not treated effectively. Extensive and rapid death of parenchyma cells of the liver (hepatic necrosis) also occurs.

Hemozoin (malaria pigment) is a disposal product formed from the digestion of red blood cells by malaria parasites, and it is observed in either the cytoplasm or outside hepatocyte and kupffer cells as black or brownish granules. On the other hand, haemosiderin is a granular brown substance composed of ferric oxide left from the breakdown of haemoglobin. It is usually observed in the cytoplasm of kupffer cells. Haemosiderosis is a form of iron overload disorder resulting in the accumulation of haemosiderin. Both haemosiderosis and hemozoin were observed in the liver, but hemozoin was more in the spleen.

In the liver, the absence of kupffer cell hyperplasia and haemosiderosis in the artesunate group is partly due to early 


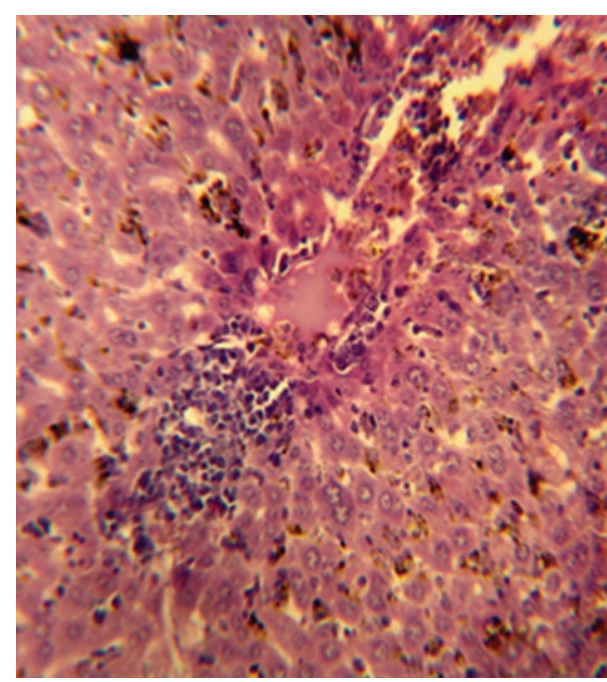

(a)

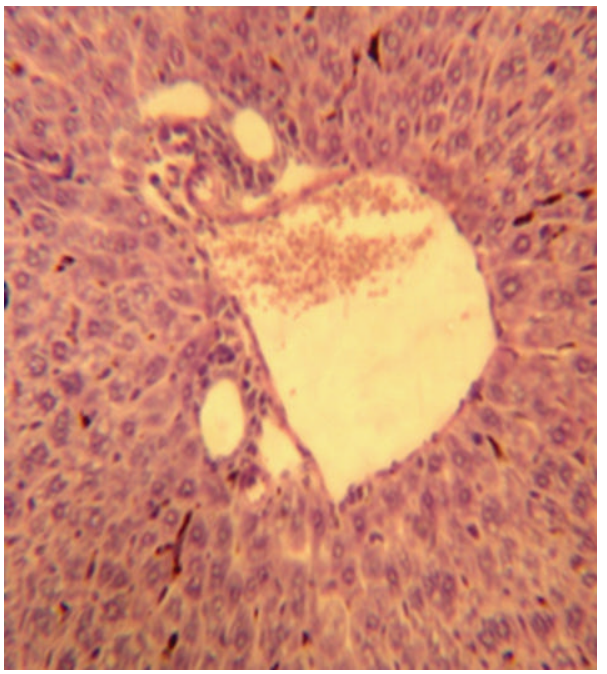

(c)

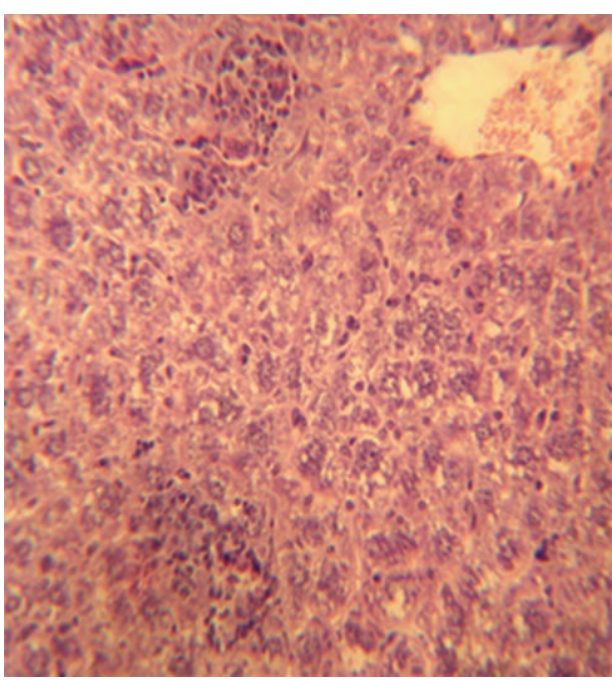

(b)

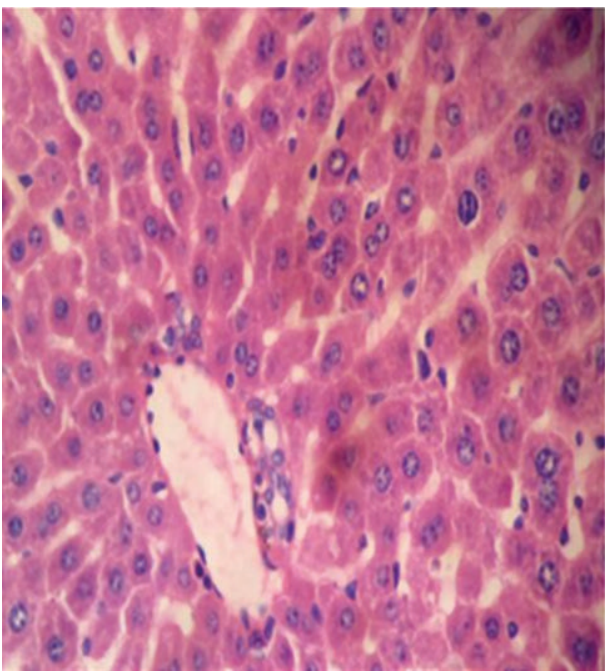

(d)

FIGURE 1: LS of control liver and treated liver under high magnification (40x). (a) Control (infected without treatment) liver: showing severe hepatic necrosis with kupffer cells hyperplasia and haemosiderosis; (b) treated (artesunate) liver: showing mild hepatic necrosis and traces of periportal mononuclear cells infiltration; (c) treated (chloroquine) liver: showing mild haemosiderosis, kupffer cell hyperplasia, and hepatic necrosis, with traces of periportal mononuclear cells infiltration; (d) control (uninfected normal) liver.

clearance of parasitaemia on the second day of treatment, but mild hepatic necrosis was still observed. Chloroquine, on the other hand, mildly reduced kupffer cell hyperplasia, haemosiderosis, and hepatic necrosis which in part may be due to the brief delay before parasite clearance (Figure 1).

In the kidney, chloroquine and artesunate totally prevented the infiltration of perivascular interstitial mononuclear cells which are located between tubules of the nephron. This may be due to the activities of these drugs to mildly reduce destruction of the nephron (tubular nephrosis) by the malaria parasites in the kidney of treated mice (Figure 3).

In the spleen, haemosiderosis was also observed. This organ is the site for the breakdown of worn-out red blood cells and stores the iron they contain. Therefore, the spleen also contributed to the accumulation of these iron molecules which was also noticed in the liver of the group treated with artesunate. Lymphoid hypoplasia (underdevelopment or reduced size in lymphatic tissue) observed in the spleen of mice treated with chloroquine and severe megakaryoblast hyperplasia caused by artesunate may likely be an indication of the toxicity of this antimalarial drugs. This is because these histological changes were not observed in the control groups. Megakaryoblast is a precursor cell to a megakaryocyte during haematopoiesis (the process involved in the formation of blood cellular components). However, previous studies had shown that chronic administration of chloroquine increased megakaryocytes, blast cells, and mast cells in the spleen of albino mice which indirectly indicate possible alteration in haemopoiesis [19, 20] (Figure 2).

In the lungs, the gradual breakdown of the thin walls of the alveoli (emphysema) was absent in the group treated with chloroquine whereas mild emphysema was observed in 


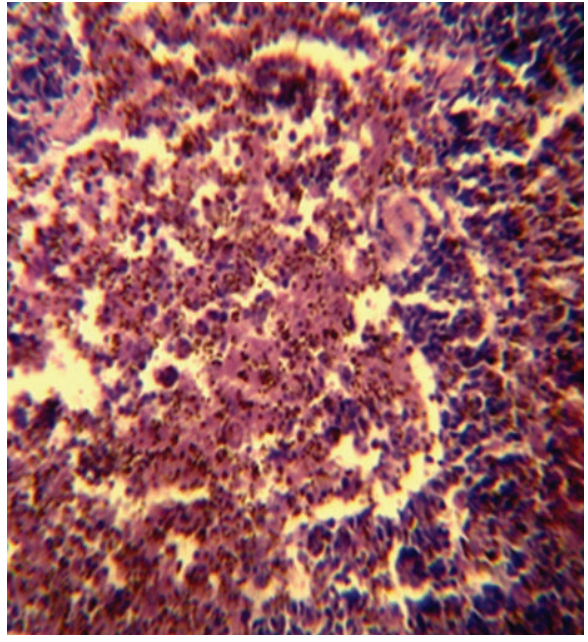

(a)

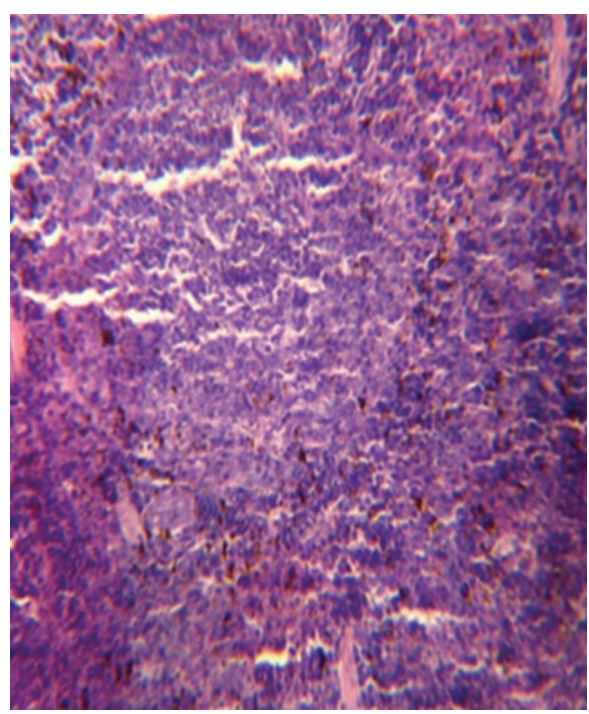

(c)

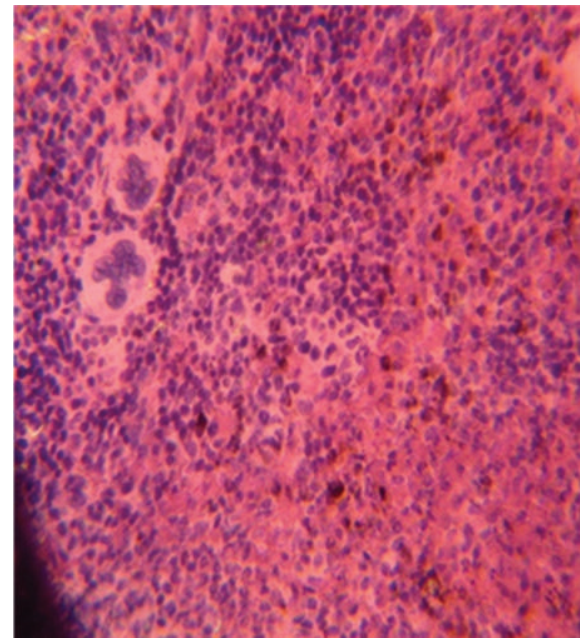

(b)

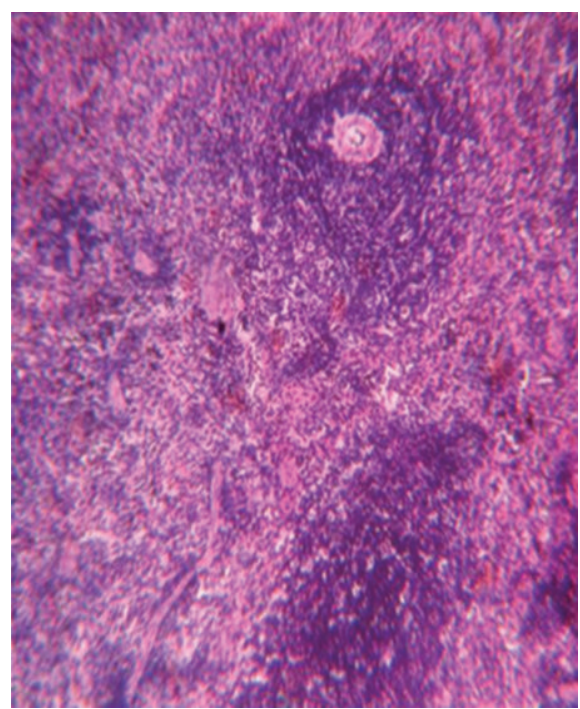

(d)

FIGURE 2: L.S. of control spleen and treated spleen under high magnification (40x). (a) Control (infected without treatment) spleen: showing severe haemosiderosis; (b) treated (artesunate) spleen: showing mild haemosiderosis and severe megakamyoblast hyperplasia; (c) treated (chloroquine) spleen: showing mild haemosiderosis and lymphoid hypoplasia; (d) control (uninfected normal) spleen.

mice treated with artesunate. Elastase is an enzyme produced by some white blood cells which destroys elastic fibres in the lungs as part of the normal turnover of elastic tissue. Its activity is normally regulated by AAT, which inhibits the enzyme. Naturally, inhibitors such as AAT ( $\alpha$-1-antitrypsin) which is produced in the liver and released into the blood prevents the breakdown of elastic tissue in the walls of the alveoli [21]. These inhibitors may become deficient since the malaria parasites had altered the normal functioning of the liver by destroying the liver cells. Therefore, the alveolar thin wall may lose its elasticity and lead to the development of emphysema in the lungs. Thickened alveolar wall was not observed in the lungs of mice treated with artesunate but mildly present in mice treated with chloroquine.

In all the organs assessed in this study except the liver, infiltration of interstitial mononuclear cells was not observed in mice treated with the drugs of study but observed only in the untreated infected control. In the liver, this observation was very mild in the treated groups but absent in the untreated infected control. From this present result, reasons for these observations cannot be stated, as well as if this observation leads to liver pathology. Further experiments such as those aimed at measuring liver enzymes in the plasma of the treated groups may be considered. This study was sponsored by the authors because we could not get a research grant as at the time the study was conducted. Hence, the experiments could not be completed.

\section{Conclusion}

This present study contributes to previous studies on pathological damages caused by the malaria parasite on vital 


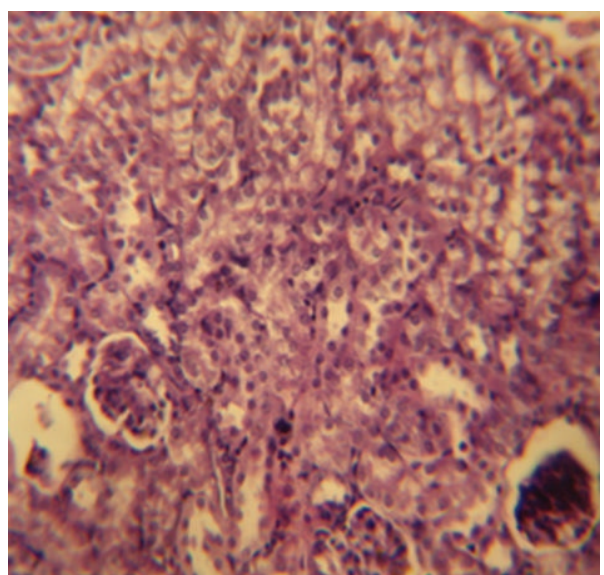

(a)

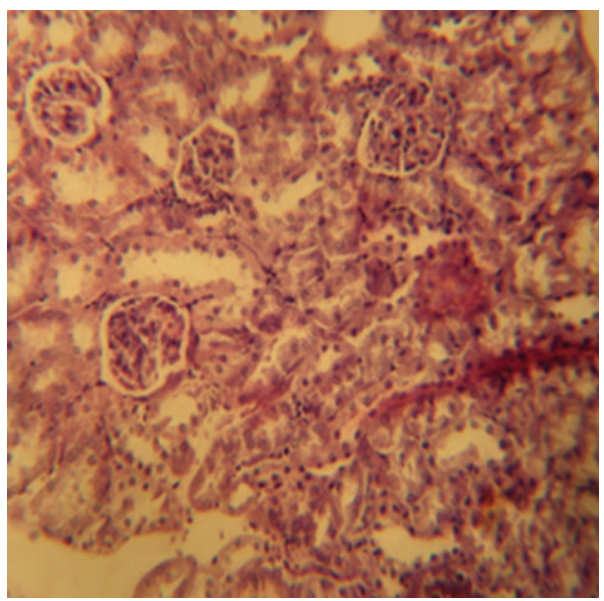

(c)

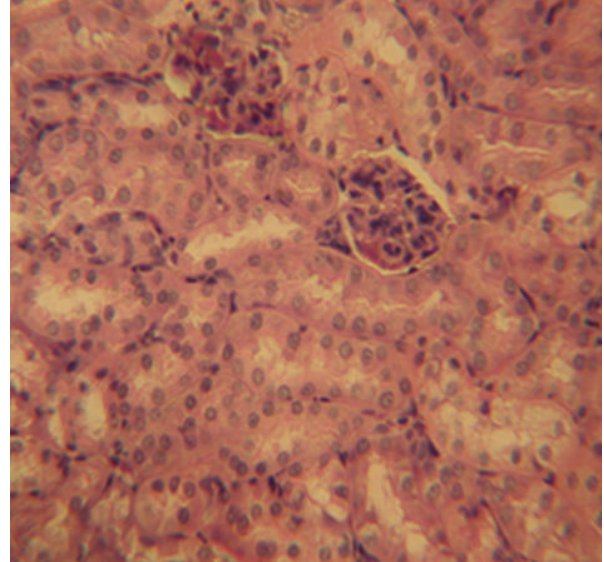

(b)

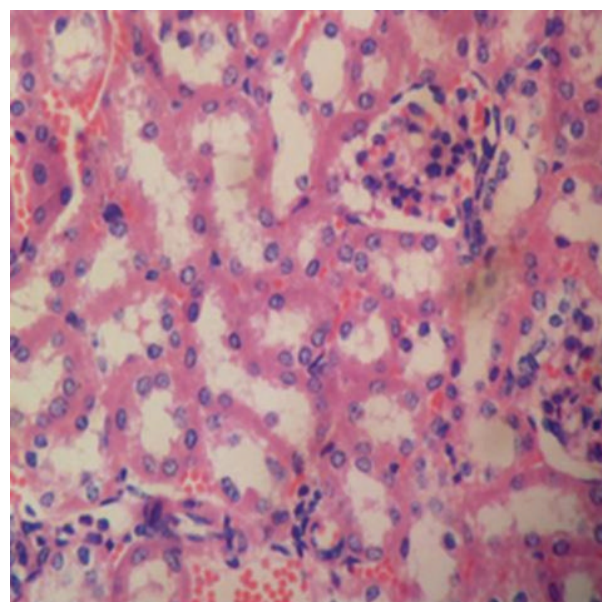

(d)

FIGURE 3: LS of control kidney and treated kidney under high magnification (40x). (a) Control (infected without treatment) kidney: showing severe tubular nephrosis and perivascular interstitial mononuclear cell infiltration; (b) Treated (artesunate) kidney: showing mild pathological changes; (c) treated (chloroquine) kidney: showing mild pathological changes; (d) control (uninfected normal) kidney.

organs. It therefore compares the effect of chloroquine and artesunate on the pathological damages of malaria in mice infected with $P$. berghei. The parasitaemia result shows that artesunate is more effective than chloroquine as observed in the number of days of parasite clearance. The observed effect of artesunate on the pathological damages caused by the malaria parasite was remarkable in the liver than the effect of chloroquine. However, this is a pilot study to future research where ACT (artemisinin combination therapy) will be assessed.

\section{Acknowledgment}

The authors could not get a financial support for this study as at the time it was carried out, but they acknowledge the technical support of Dr. Olufemi Aina of the Biochemistry Unit, National Institute of Medical Research, Yaba, Lagos.

\section{References}

[1] African Medical and Research Foundation (17/062012), Malaria, New York, NY, USA, http://www.usa.amref.org/.

[2] A. W. Obianime and J. S. Aprioku, "Comparative study of artesunate, acts and their combinants on the hormonal parameters of the male guinea-pig," Nigerian Journal of Physiological Sciences, vol. 24, no. 2, pp. 101-106, 2009.

[3] A. M. Izunya, A. O. Nwaopara, A. E. Aigbiremolen, M. A. C. Odike, G. A. Oaikhena, and J. K. Bankole, "Histological studies of the toxicity of artesunate on the testes in Wistar rats," Biology and Medicine, vol. 2, no. 2, pp. 49-56, 2010.

[4] R. A. B. Drury, E. A. Wallington, and R. Cameron, Carleton's Histological Techniques, Oxford University, New York, NY, USA, 4th edition, 1967.

[5] World Heath Organization, Media Centre on Malaria: Fact sheet, 2010, http://www.who.int/mediacentre/factsheets/ fs094/en/index.html.

[6] R. Kyle and M. Shampe, "Discoverers of quinine," Journal of the American Medical Association, vol. 229, no. 4, p. 462, 1974. 
[7] S. Pattanasin, S. Proux, D. Chompasuk et al., "Evaluation of a new Plasmodium lactate dehydrogenase assay (Optimal-IT) for the detection of malaria," Transactions of the Royal Society of Tropical Medicine and Hygiene, vol. 97, no. 6, pp. 672-674, 2003.

[8] W. Peters, "Drug resistance in malaria parasites of animals and man," Advances in Parasitology, vol. 41, pp. 1-62, 1998.

[9] J. Neequaye, J. Coene, and H. Taelman, "In vivo chloroquineresistant falciparum malaria in Western Africa," The Lancet, vol. 1, no. 8473, pp. 153-154, 1986.

[10] Afrique Avenir, Nigeria to phase out chloroquine for malaria treatment. (news report published November 30th, 2010), 2010, http://www.afriqueavenir.org/en/2010/11/30/nigeriato-phase-out-chloroquine-for-malaria-treatment/.

[11] T. T. Hien, "An overview of the clinical use of artemisinin and its derivatives in the treatment of falciparum malaria in Vietnam," Transactions of the Royal Society of Tropical Medicine and Hygiene, vol. 88, supplement 1, pp. 7-8, 1994.

[12] T. Harinasuta and J. Karbwang, "Qinghaosu: a promising antimalarial," Journal of American Medical Association, SEA, vol. 34, pp. 7-8, 1994.

[13] N. J. White, "Qinghaosu (artemisinin): the price of success," Science, vol. 320, no. 5874, pp. 330-334, 2008.

[14] H. Nwanjo and G. Oze, "Acute hepatotocixity following administration of artesunate in guinea pigs," The Internet Journal of Toxicology, vol. 4, no. 1, 2007.

[15] A. F. David, J. R. Philip, R. C. Simon, B. Reto, and N. Solomon, "Antimalarial drug discovery: efficiency models for compound screening," Nature Reviews, vol. 3, pp. 509-520, 2004.

[16] L. T. Peter and V. K. Anatoli, "The current global malaria situation," in Malaria Parasite Biology, Pathogenesis and Protection, pp. 11-22, ASM Press, Washington, DC, USA, 1998.

[17] O. T. Soniran, O. A. Idowu, and O. O. Ajana, "Evaluation of in vivo antiplasmodial activities of extract of morinda morindiodes (Bak.) in the treatment of malaria in Ogun State," International Journal of Biomedical and Health Sciences, vol. 7, no. 3, 2011.

[18] P. C. C. Garnham, Malaria Parasites and Other Heamosporidia, Blackwell Scientific, Oxford, UK, 1966.

[19] K. R. Desai, J. J. Dattani, D. K. Rajput et al., "Effect of chronic administration of chloroquine on the gastrocnemius muscle, spleen and brain of Swiss albino mice," Asian Journal of Traditional Medicines, vol. 5, no. 2, pp. 62-69, 2010.

[20] T. Othman and R. O. A. Arowolo, "Effects of incremental doses of chloroquine phosphate on the formed elements of blood," Tropical Medicine, vol. 40, no. 1, pp. 1-7, 1998.

[21] D. J. Taylor, N. P. O. Green, and G. W. Stout, Biological Science, Cambridge University, Cambridge, UK, 3rd edition, 2008. 


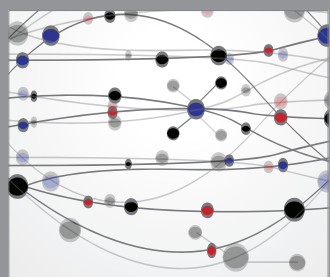

The Scientific World Journal
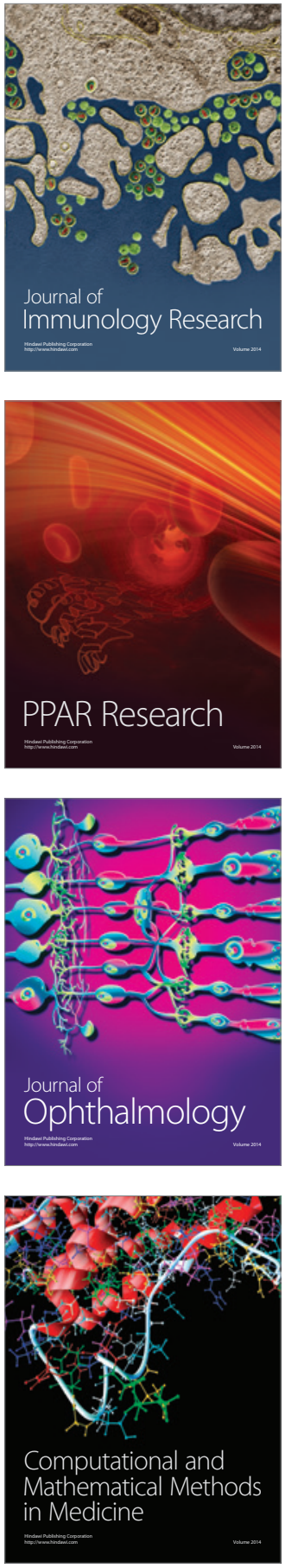

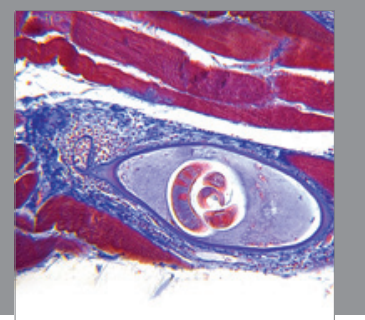

Gastroenterology

Research and Practice
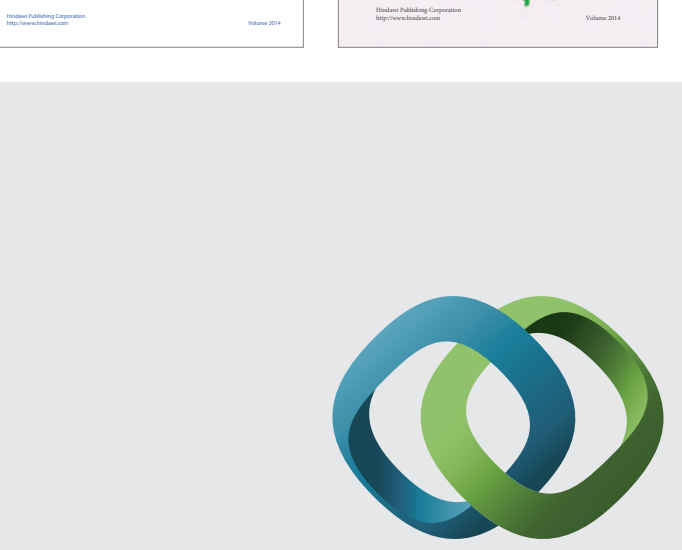

\section{Hindawi}

Submit your manuscripts at

http://www.hindawi.com
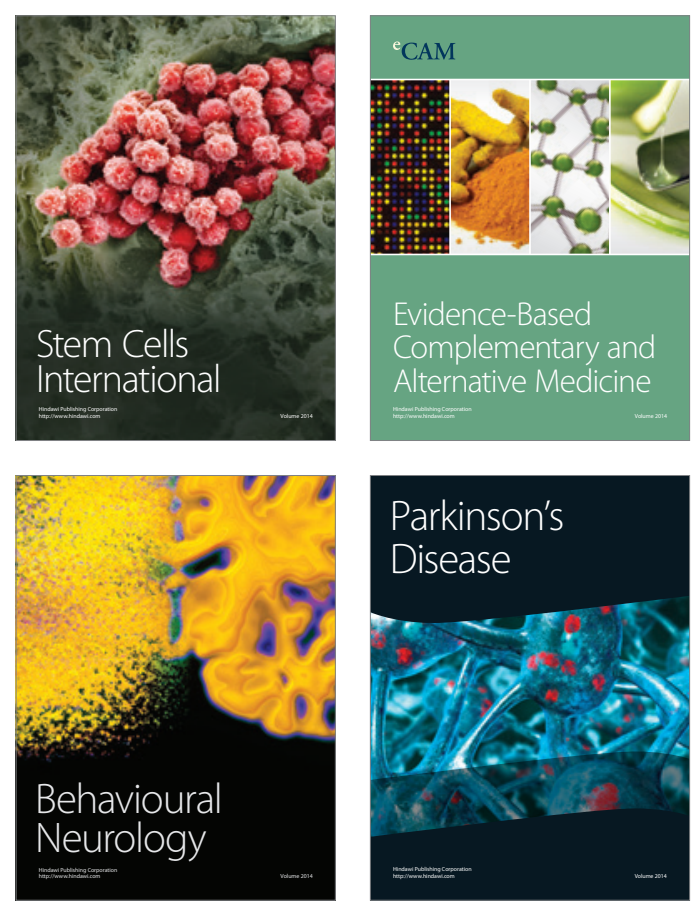

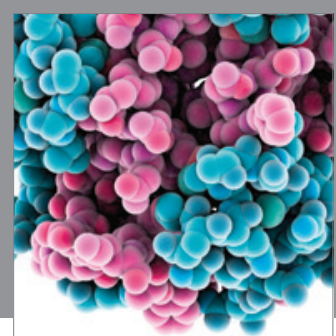

Journal of
Diabetes Research

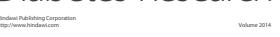

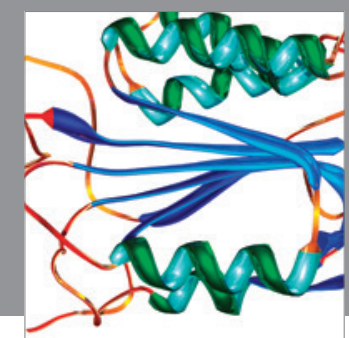

Disease Markers
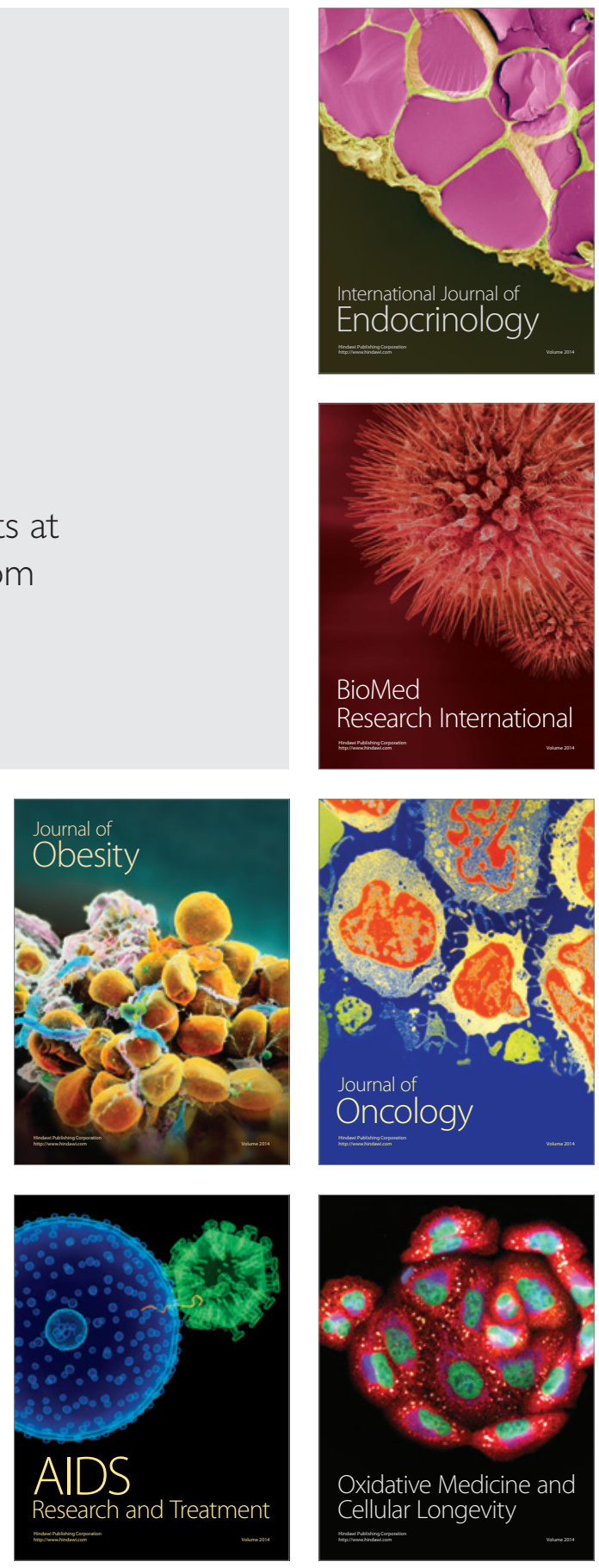